CORRESPONDENCE

\section{Incremental value of pulmonary artery diameter indexed for BSA in pulmonary hypertension}

With great interest, we read the article by Rajaram et $a l^{1}$ regarding the prevalence and prognostic value of CT measures in patients with pulmonary arterial hypertension. They found the inferior vena cava area and presence of pleural effusion or septal lines to be the only significant predictors of mortality. A vascular parameter, the ratio of the pulmonary artery (PA) to ascending aorta (Ao), was no predictor for mortality during a mean follow-up of 3 years. ${ }^{1}$ A better vascular parameter might be the PA indexed for body surface area (BSA). However, in their study this was not taken into account.

The non-invasive diagnostic and prognostic approach to pulmonary hypertension $(\mathrm{PH})$ is challenging. In patients with $\mathrm{PH}$, dilatation of the main $\mathrm{PA}$ is common. As a result, different parameters including the main PA diameter, PA to Ao ratio and PA indexed for BSA have been identified as reliable predictors of $\mathrm{PH}$ and additionally show good correlation with mean PA pressure as measured by right heart catheterisation. Interestingly, the correlation improved significantly after correction for BSA. $^{2}$ Unfortunately, less is known regarding PA parameters in relation to outcome.

Similarly as reported in this study, Schölzel $e t a l^{3}$ could not correlate PA to Ao ratio with mortality in a subgroup of $\mathrm{PH}$. However, they showed that the PA diameter indexed for BSA was an independent predictor of mortality, suggesting this could be a more distinct parameter compared with PA to Ao ratio. Both ascending aorta and PA measurements are known to be influenced by BSA. $^{4}{ }^{5}$ However, whether both measurements are affected equally is unknown. Variation of influence by BSA might explain the inaccuracy of PA to Ao ratio and potential superiority of PA indexed to BSA to predict mortality.

We reckon the study of Rajaram $e t$ al is highly valuable, although PA indexed for BSA is lacking. We respectfully propose to integrate PA diameter indexed for BSA into their data since it is easily calculated and can be of incremental value upon absolute PA diameter or PA to Ao ratio in order to evaluate the prognosis and clinical outcomes in PH.

Marloes P Huitema, ${ }^{1}$ Herre J Reesink, ${ }^{2}$ Martijn C Post ${ }^{1}$

${ }^{1}$ Department of Cardiology, St. Antonius Hospital, Nieuwegein, The Netherlands

${ }^{2}$ Department of Pulmonology, St. Antonius Hospital, Nieuwegein, The Netherlands

Correspondence to Marloes Petra Huitema,

Cardiology, St. Antonius Hospital,

Nieuwegein 3435CM, The Netherlands;

mp.huitema@antoniusziekenhuis.nl

Contributors HJR found the article for correspondence. MPH performed research for relevant literature and generated the manuscript. HJR and MCP reviewed the manuscript regarding the content and spelling.

Competing interests None declared.

Provenance and peer review Not commissioned; internally peer reviewed.

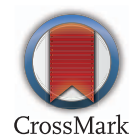

To cite Huitema MP, Reesink HJ, Post MC. Thorax 2015;70:1087.

Received 20 May 2015

Accepted 8 June 2015

Published Online First 23 June 2015

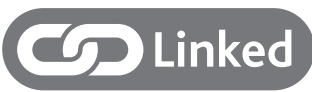

- http://dx.doi.org/10.1136/thoraxjnl-2014-206088

- http://dx.doi.org/10.1136/thoraxjnl-2015-207394

Thorax 2015;70:1087.

doi:10.1136/thoraxjnl-2015-207328

\section{REFERENCES}

1 Rajaram S, Swift AJ, Condliffe R, et al. CT features of pulmonary arterial hypertension and its major subtypes: a systematic CT evaluation of 292 patients from the ASPIRE Registry. Thorax 2015;70: 382-7.

2 Kuriyama K, Gamsu G, Stern RG, et al. CT-determined pulmonary artery diameters in predicting pulmonary hypertension. Invest Radiol 1984;19:16-22.

3 Schölzel BE, Post MC, Dymarkowski S, et al. Prediction of outcome after PEA in chronic thromboembolic pulmonary hypertension using indexed pulmonary artery diameter. Eur Respir J 2014:43:909-12.

4 Truong QA, Massaro JM, Rogers IS, et al. Reference values for normal pulmonary artery dimensions by noncontrast cardiac computed tomography: the Framingham Heart Study. Circ Cardiovasc Imaging 2012:5:147-54.

5 Wolak A, Gransar H, Thomson LEJ, et al. Aortic size assessment by noncontrast cardiac computed tomography: normal limits by age, gender, and body surface area. JACC Cardiovasc Imaging 2008;1:200-9. 